\title{
Otobüs İçi Yoğunluk Oranını Dikkate Alan Bulanık Optimal Güzergah Öneri Modeli ve Çözüm Algoritması
}

\author{
Resmiye NASIBBOĞLU(D)
}

Dokuz Eylül Üniversitesi, Fen Fakültesi, Bilgisayar Bilimleri Bölümü, 35390, İzmir, Türkiye

(Alınış / Received: 09.03.2021, Kabul / Accepted: 01.06.2021, Online Yayınlanma / Published Online: 15.08.2021)

\author{
Anahtar Kelimeler \\ Bulanık modelleme, \\ Optimizasyon, \\ Algoritma, \\ Toplu taşıma ağı, \\ Optimal güzergah
}

\begin{abstract}
Özet: Toplu taşıma araçlarının etkin șekilde kullanılması, akıllı șehir konseptine katkı sağlayacak bileșenlerden biridir. Bu bakımdan, toplu taşıma araçlarının kullanımını kolaylaştıran uygulamaların geliştirilmesi önem kazanmaktadır. Bu çalışmada, bu alanda yapılacak uygulamalara destek olabilecek bir bulanık optimal güzergah öneri modeli ve çözüm algoritması geliştirilmiştir. Bu modelin diğer çalışmalardan esas farkı otobüs içi yoğunluk oranını da dikkate alan bulanık güzergah tercih derecesinin tanımlanmasıdır. Günümüz pandemi sürecinde otobüs içi yoğunluğu dikkate alabilen modelin önemi daha da artmaktadır. Oluşturulan modelde, klasik modellerin aksine, her güzergah, bulanık tercih derecesi eşliğinde önerilmektedir. Çözüm algoritması, bulanık ceza değerleri kullanan Dijkstra benzeri bir algoritmadır. İzmir toplu taşıma ağı verileri kullanılarak yapılan simülatif deneyler yapılmıştır. Önerilen bulanık modele uygun olarak hesaplanan optimal çözümlerin, bulanıklık konsepti kullanmayan klasik yaklaşımdan tercih dereceleri daha yüksek olan çözümler ürettiği görülmüştür.
\end{abstract}

\section{A Fuzzy Optimal Route Suggestion Model and Solution Algorithm Considering Inside Bus Occupation Rate}

\section{Keywords}

Fuzzy modeling,

Optimization,

Algorithm,

Public transport network, Optimal route

\begin{abstract}
Effective use of public transport is one of the components that will contribute to the smart city concept. In this respect, it is important to develop applications that facilitate the use of public transportation vehicles. In this study, a fuzzy optimal route suggestion model and solution algorithm has been developed that can support the applications in this field. The main difference of this model from other studies is the definition of the fuzzy route preference degree, which also takes into account the occupation density rate of the bus. In today's pandemic process, the importance of the model that can take into account the occupation density in the bus increases even more. In the created model, on the contrary of classical models, each route is suggested with fuzzy preference degree. The solution algorithm is a Dijkstra-like algorithm that uses fuzzy penalty values. Simulative experiments have been conducted using the Izmir public transport network data. It has been observed that the optimal solutions calculated in accordance with the proposed fuzzy model produce solutions with higher preference degrees than the classical approach that does not use the concept of fuzziness.
\end{abstract}

\section{Giriş}

Akıllı şehirler, trafik sıkışıklığı vs. gibi konular, son zamanlarda üzerine çok konuşulan konulardandır. Akıllı şehirlerde trafik kalabalığının önüne geçilmesi için etkin enstrümanlardan biri de toplu tașıma kullanımının teşvik edilmesidir. Yolcu isteklerinin karşılanmasına yönelik uygulamalar bu bakımdan önem kazanmaktadır. Bu doğrultuda, toplu taşımada yolculuğun kolaylaşması ve etkin planlama için veri toplanması amacıyla çeşitli otomasyon sistemleri kullanılmaktadır. Otomatik sistemler şu şekilde tanımlanır: Otomatik Ücret Toplama Sistemleri (AFC), konuma dayalı Otomatik Araç Konumlama (AVL) ve sensörleri kullanarak uçağa binen ve inen yolcuların sayısını sayan Otomatik Yolcu Sayma (APC) sistemleri [1]. Büyük şehirlerin çoğunda kullanılan akıllı ücret toplama kartları aracılığıyla ücretin yanı sıra, çok 
sayıda veri toplanmaktadır. Otomatik sistem üzerinden elde edilen veriler son 20 yılda toplu taşıma planlamasında etkin şekilde kullanılmaktadır [2]. Bagchi ve ark. [3] ilk defa İngiltere'deki iki otobüs şirketinden alınan verileri kullanarak akıllı kart verilerinin doğasını incelemiştir. Morency ve ark. [4] Gatineau, Quebec'te yolcu davranışlarını belirlemek için on aylık biniş verilerini incelemiştir. Toplu taşıma modellerinin oluşturulduğu ve otomatik sistemlerdeki akıllı kartların veri kaynağı olarak kullanıldığı diğer bir çalışma da [5] çalışmasıdır.

Menşe-Varış Noktası (OD) matrisi, toplu taşıma sistemlerinin planlanması için kritik bir bilgi olan yolcu akışını belirlemektir. Nasibov ve ark. [6] çalışmasında İzmir kenti için akıllı ulaşım kartı verileri bazında OD matrisi hesaplanmışlardır. Munizaga ve Palma [7] çalışmasında, Santiago, Şili'deki büyük ulaşım ağı için hem akıllı kart hem de GPS verilerinden OD matrisini tahmin etmek için bir metodoloji sunmuştur. Barry ve ark. [8] çalışmasında, New York'ta sadece kentsel raylı sistem üzerinden biniş işlemlerine dayalı analizler içeren durumu ele almıştır. Trepanier ve ark. [9] çalışmasında bir otobüse binen her bir bireyin varış yerini tahmin etmek için bir model önermiştir. Diker [10] doktora tez çalışmasında da İzmir kent akıllı kart verilerine dayalı iniş tahminlerini yapmıştır. Bu amaçla yolculuk zinciri yöntemi kullanılmıştır. Yolculuk zinciri, yolcuların siralı hareketlerini incelemeye dayandığından, iniş bilgisini tahmin etmek için literatürde iyi bilinen bir yöntemdir. Bu çalışmada, en az transfer, en kısa yolculuk mesafesi gibi kriterlere dayalı model geliştirilmiştir.

Mobil cihazların yaygınlaşması ile birlikte optimal güzergah öneri çalışmaları ve uygulamaları da yaygınlaşmıştır. Bu çalışmalarda yolcuların seyahat önceliklerini dikkate alarak en uygun güzergah önerilmesi modelleri ele alınmıștır. Çalıșmaların çoğunda belli menşe ve varış noktaları arasında en az sayıda duraktan geçen en kısa güzergah, en az yolculuk zamanı, en az sayıda hat değiştirilerek transfer yapılması gibi kriterler dikkate alınmaktadır. Bazı modellerde en kısa zaman kriteri de ele alınmaktadır. Örneğin, [11-13] çalışmalarında P uzay modeli kullanılarak en az sayıda geçilen durak sayısı, en kısa yürüme mesafesi, en az transfer sayısı gibi kriterlere göre çok kriterli optimal güzergah öneri modeli oluşturulmuştur. Wang ve ark. [14] çalışmasında Dijkstra algoritmasına dayalı duraklar arası en kısa yol belirleme problemi ele alınmıștır. Pun-Cheng ve Chan [15] çalışmasında Hong Kong kentinde ring şeklinde olan hatlar için optimizasyon problemi ele alınmıştır. Huang ve ark. [16] makalesinde Çinin Wuhan kentinde transit yolcuların gereksinimlerini dikkate alan çalışma yapılmıştır.

$\mathrm{Bu}$ çalışmaların ekseriyetinde kullanılan durakların veya hatların nitelik anlamda değerlendirilmesi yapılmamaktadır. Fakat, Nasibov ve ark. [17] çalışmasında toplu taşımacılıkta optimal seyahat planlamaya bulanık bir yaklaşım önerilmiştir. Bu çalışmada biniş ve iniş durakları seçildiği zaman, en uygun güzergah önerilerini sunan bir model oluşturulmuştur. Çalışmada önerilen modelde duraklar için uygunluk kavramları tanımlanmıştır. Her durak fiziksel mesafe anlamında yakınlık, binişiniş yoğunluğu ve hatların yoğun olarak geçmesi gibi bakış açlarından değerlendirilmiştir. Değerlendirmeler bulanık mantık yaklaşımıyla derecelendirilerek gerçekleştirilmiştir. Tüm bu bulanık derecelerden durak için genel bir uygunluk derecesi hesaplanmıştır ve güzergâh planlaması, durak uygunlukları dikkate alınarak yapılmıştır.

Önceki çalışmalarda genel olarak, güzergâh planlamasında belli duraklar arasında hattın olup olmadığı esas alınmaktadır, yani hatlar uygunluk açısından sadece 0/1 mantığıyla ele alınıyorlar. Fakat, günümüzde bulaşıcı pandemi salgınının etkin olduğu bir dönemde, hatlardaki otobüs içi doluluk oranlarının dikkate alınması kritik olarak öne çıkan faktörlerden biri haline gelmiștir. Dolayısıyla belli bir güzergâh planlamasında bu faktörün dikkate alınması çok önemlidir. Bu çalışmada, güzergâh planlamada öngörülen otobüs içi doluluk oranlarına göre belli bir derecelendirme oluşturulmaktadır ve bu yaklaşım en uygun güzergah planlamasında dikkate alınmaktadır. Otobüs içi doluluk oranlarının hesaplanmasında Diker [10] çalışmasında ele alınan teknikler kullanılmaktadır. Söz konusu çalışmada, akıllı kart kullanımıyla kayıt altına alınan biniş bilgileri analiz edilerek her hat için durak bazlı otobüs içi yoğunluğun hesaplanması yapılabilmektedir. Doluluk oranı bilgisi yolcunun güzergah seçiminde dikkate aldığı önemli bir bilgidir. Bu makalede ise, en uygun güzergâh planının olușturulması zamanı yolcunun karar verme stratejisi, yolculuk süresince otobüs içi en yüksek yoğunluk derecesi olarak dikkate alınmaktadır.

Makalenin devamında, 2. Bölümde iniş duraklarının tahmin edilmesinde kullanılan seyahat zinciri yöntemi ve neticede otobüs içi bulanık yoğunluk derecesinin hesaplanması yöntemi verilmiştir. Devamında, olası bağlantı, olası bulanık bağlantı gibi kavramlar hakkında bilgiler ve bulanık güzergah tercih derecesi kavramı verilmiş, bu kriterin yanı sıra en az geçilen durak sayısı, en az hat transfer sayısı gibi kriterlere dayanan çok kriterli bulanık optimal güzergah öneri modeli tanımlanmıştır. Önerilen modelin çözümü için geliştirilen bulanık ceza fonksiyonu kullanan Dijkstra benzeri bir algoritma verilmiştir. 3. Bölümde, Izmir toplu taşıma ağının verileri kullanılarak hesaplama denemeleri yapılmış ve önerilen model ve algoritmanın avantajları ve dezavantajları değerlendirilmiştir. Sonuç ve Tartışma bölümünde, çalışmanın esas sonuçları belirtilmiş, ileriye yönelik çalışmalar hakkında ipuçları verilmiştir. 


\section{Materyal ve Metot}

\subsection{Otobüs İçi Yoğunluğun Tahmin Edilmesi}

Toplu taşımada genel olarak ücret toplama amaçlı kullanılan akıllı kartlarla her biniş esnasında ücret toplamanın yanı sıra, akıllı kartın ID'si, binișin zamanı, biniş yapılan durak, biniş yapılan hat, biniş yapılan otobüs bilgileri de toplanmaktadır. Genellikle bu bilgiler gün sonunda sunucuya yüklenmektedir. Yapılan analizler anlık olmayıp, gün sonu bilgilerine dayal hesaplanabilmektedir. Nasibov ve ark. [6] ve Diker [10] çalışmalarında İzmir BB ESHOT Genel Müdürlüğü verilerine göre yolculuk zinciri yöntemi kullanılarak iniş tahminleri yapılmıştır. Bu çalışmada ise, biniş ve iniş bilgileri kullanılarak her hatta yer alan sefer bazlı ortalama otobüs içi yoğunluk bilgileri hesaplanmaktadır. Bu bilgiler saat bazında veya günün belli periyotlarında ortalama değerler olarak hesaplanabilmektedir. Açıktır ki, akıllı kart aracılığıyla yapılan biniș bilgileri anlık olarak sunucuya iletilebilseydi, bu analizler anlık otobüs içi yoğunluk olarak da hesaplanabilirdi. $\mathrm{Bu}$, teknik olarak yapılabilir, ama çok maliyetlidir. Bu bakımdan, veriler anlık değil, gün sonu olarak sunucuya yüklenmektedir ve yapılan analizler de uygun olarak günlük gecikmeyle yaplabilmektedir.

Seyahat zinciri yöntemi, sadece biniş bilgileri bulunan akıllı kart verilerinden iniș bilgilerinin tahmin edilmesi için kullanılan yöntemdir. Currie ve Delbosc [18] çalışmasında Avustralya'nın Melbourne kentinde seyahat zinciri yöntemi kullanılarak yolcu davranışları analiz edilmiştir. Seyahat zinciri yöntemi genel olarak aşağıdaki varsayımlara dayanmaktadır:

a) İniş durağı, biniş hattı üzerindedir;

b) İniş durağı biniş durağından sonra olmalıdır;

c) İniş durağı, a) ve b) koşullarını sağlayan duraklar kümesinden olan ve bir sonraki biniş durağına en yakın olan duraktır.

Yukarıdaki varsayımlarda güzergahtaki en son binișten sonraki iniş durağının tahmin edilmesinde zorluklar yaşanmaktadır. Bu durumda iniş durağı olarak hat üzerindeki en son durak atanabilir. Daha detaylı yaklaşımlarda ise iniş durağı, hat üzerindeki durakların biniş-iniş istatistikleri dikkate alınarak tahmin edilebilir. İlk biniş A durağl ve ikinci biniş B durağı olduğu durumda, seyahat zinciri yöntemiyle ilk binişten sonraki tahmin olunan iniş durağı şematik olarak Şekil 1'de yansıtılmıştır.

Yukarıda belirtildiği gibi, akıllı kart aracılığıyla her biniş için; biniş zamanı, biniş durağı, biniş hattı, biniş otobüs numarası gibi bilgiler kaydedilmektedir. Bu bilgilerden her hat üzerindeki belirli otobüse hangi durakta kaç kişi bindiği çıkarılabilir. Öte yandan, seyahat zinciri tekniği kullanılarak her kișinin hangi durakta indiği de tahmin edilebilir. Dolayısıyla her durakta her otobüse kaç kişinin bindiği ve indiği bilgisi, buradan da bindi-indi farkına göre otobüs içi yoğunluk çıkarılabilir.

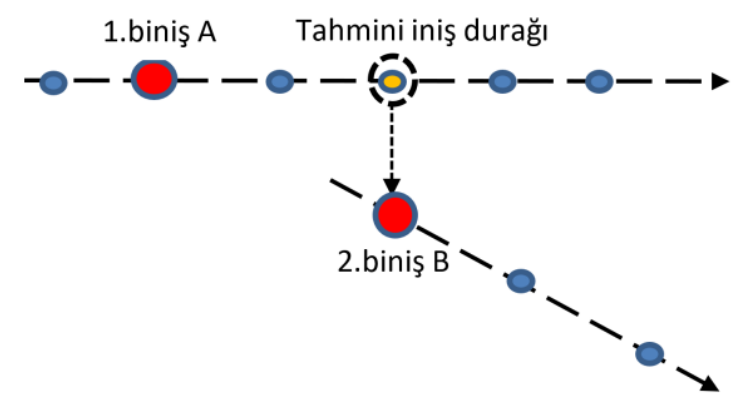

Şekil 1. Seyahat zinciri yöntemiyle iniş durağının tahmin edilmesi.

$b_{i}, i=1, \ldots, n$, ile belli hat üzerindeki belli otobüse $i$. duraktaki biniş sayısı olarak işaretlensin. Açıktır ki bu bilgi, akıllı kart verilerinden basit bir SQL sorgusuyla alınabilir. Ayrıca, aynı otobüsten aynı duraktaki iniş sayısı $a_{i}, i=1, \ldots, n$, olsun. $\mathrm{Bu}$ durumda, hat üzerindeki $i$. duraktan kalkış sonrası otobüs içi yolcu sayısı $p_{i}$, aşağıdaki şekilde hesaplanabilir:

$$
\begin{gathered}
p_{i}=\sum_{k=1}^{k \leq i}\left(b_{k}-a_{k}\right), i=1, \ldots, n, \\
a_{1}=0 \\
b_{n}=0
\end{gathered}
$$

(2) ile (3) denklemleri, sırasıyla hat üzerindeki ilk durakta inişin ve son durakta binişin olmadığını göstermektedirler.

\subsection{Yoğunluğa Göre Hat Tercih Derecesi ve Olası Bulanık Bağlantı}

Rota planlamasına yönelik harita kullanan uygulamalarda bir duraktan diğerine yürüyerek geçiş zamanı iniş ve biniş durakları arası uzaklıklar veya ilk biniş ve son iniş duraklarından belli gereken menșe ve hedef konumlarına olan uzaklıklar önem arz etmektedir. Bu durumda, harita üzerinde belli enlem ve boylam koordinatlarıla verilmiş iki $X\left(\varphi_{1}, \lambda_{1}\right)$ ve $Y\left(\varphi_{2}, \lambda_{2}\right)$ noktaları arasında uzaklı haversine formülüne göre hesaplanabilir:

$$
\begin{gathered}
d(X, Y)=2 \cdot R \cdot \sin ^{-1} \\
\left(\left[\sin ^{2}\left(\frac{\varphi_{1}-\varphi_{2}}{2}\right)+\cos \varphi_{1} \cdot \cos \varphi_{2}\right.\right. \\
\left.\cdot \sin ^{2}\left(\frac{\lambda_{1}-\lambda_{2}}{2}\right)\right]^{0.5}
\end{gathered}
$$

Burada, $R$, Yerkürenin yarıçapıdır $(R=6367450 \mathrm{~m})$.

Sonraki modellememizde yardımcı olacak bazı tanımları verelim. Tüm duraklar kümesini $S$ ve tüm hatlar kümesini $L$ olarak ișaretleyelim. Bu durumda her bir $l \in L$ hattı, onun geçtiği $s \in S$ duraklarının sıralı dizisi şeklinde verilebilir. Bunu hat-durak ilişkisi şeklinde aşağıdaki gibi tanımlayabiliriz: 
$L S(l, s)=$

$\{i, \quad s$ dură̆, l hattının üzerindeki i.duraktır,

$\{0, \quad s$ dură̆ $l$, hattının üzerinde de ğildir.

Belli bir $l$ hattının geçtiği duraklar kümesi,

$$
S(l)=\{s: L S(l, s) \geq 1\}
$$

olarak işaretlensin. Așağıdaki koşulları sağlayan bir $\left(s_{b}, l, s_{a}\right)$ üçlüsü, $s_{b}$ biniş durağı ile $l$ hattı kullanarak $s_{a}$ iniş durağı arasında olası bir bağlantıdır:

$$
\begin{gathered}
s_{b} \in S(l) \\
s_{a} \in S(l) \\
L S\left(l, s_{b}\right)<L S\left(l, s_{a}\right)
\end{gathered}
$$

Diğer yazılışla, bir $\left(s_{b}, r, s_{a}\right)$ üçlüsü aşağıdaki koşulları sağlamaktadır:

$$
\begin{gathered}
L S\left(l, s_{b}\right) \geq 1 \\
L S\left(l, s_{b}\right)<L S\left(l, s_{a}\right)
\end{gathered}
$$

$\left(s_{b}, l, s_{a}\right)$ üçlüsünün bir olası bağlantı olması koşuluyla, $l$ hattı üzerindeki $s_{b}$ ile $s_{a}$ durakları arasındaki duraklar kümesini $S\left(s_{b}, l, s_{a}\right)$ olarak işaretlenecektir.

$l$ hattı üzerindeki s durağından hareket eden bir otobüsün doluluk oranını, diğer deyişe otobüs içi bulanık yoğunluk derecesini $\mu(l ; s)$ olarak gösterelsin. $\mathrm{Bu}$ bulanıklık derecesi, otobüs içindeki yolcu sayısının bu otobüs tipi için yol verilen maksimum yolcu sayısına oranı şeklinde hesaplana bilir, yani:

$$
\mu(l ; s)=\left\{\begin{array}{cr}
\frac{p_{i}}{p_{\max }}, & \text { if } p_{i} \leq p_{\max } \\
1, & \text { d.d. }
\end{array}\right.
$$

Burada $p_{i}$, i. duraktan harekete bașlarken otobüs içi yolcu sayısı, $p_{\max }$ ise bu otobüs modeli için yol verilen maksimum yolcu sayısıdır.

Yolculuk zamanı bir yolcunun otobüse bindiği $s_{b}$ durağı ile iniş yaptığı $s_{a}$ durağı arasında farklı otobüs içi yoğunluk derecelerine maruz kalmaktadır. Değerlendirmelerde kullanılmak üzere bu farklı derecelerin ortalaması, maksimumu, minimumu vs. gibi toparlanmıș (aggregated) değerler ele alına bilir. Örneğin, $s_{b}$ ile $s_{a}$ durakları arasındaki $l$ hattı boyunca toparlanmış otobüs içi bulanık yoğunluk derecesi aşağıdaki şekilde hesaplanabilir:

$$
\mu^{Y o \breve{g}}\left(s_{b}, l, s_{a}\right)=\max _{s \in S\left(s_{b}, l, s_{a}\right)} \mu(l ; s)
$$

Burada $S\left(s_{b}, l, s_{a}\right), l$ hattı üzerindeki $s_{b}$ ile $s_{a}$ durakları arasındaki duraklar kümesidir ve (10) ve (11) koşullarını sağlamaktadır.
Belli bir olası bağlantıda otobüs içi yoğunluk derecesi dikkate alınırsa, yolcu tercihi bakımından bulanık hat tercih derecesi oluşabilmektedir. Bulanık olası bağlantı kavramı, belli bir olası bağlantının klasik 0/1 mantığıyla değil, bulanık hat tercih derecesiyle gerçekleştiğini kabul etmektedir. Açıktır ki, yolcu hat tercih derecesi otobüs içi yoğunluk derecesi ile ters orantılıdır. Örneğin, belli bir $\left(s_{b}, l, s_{a}\right)$ olası bağlantısının bulanık hat tercih derecesi en basit şekilde aşağıdaki gibi belirlenebilir:

$$
\mu^{H a t}\left(s_{b}, l, s_{a}\right)=1-\mu^{Y o \breve{g}}\left(s_{b}, l, s_{a}\right)
$$

(14) formülünden göründüğü üzere, otobüsün tam dolu olduğu durumda $\left(s_{b}, l, s_{a}\right)$ olası bağlantısının bulanık hat tercih derecesi 0 olacaktır, dolayısıyla bu durum kesinlikle çözüm uzayında yer almayacaktır. Fakat gerçek hayatta bazı yolcu bu durumu da tercih edebilir. $\mathrm{Bu}$ bakımdan bu durumun da tercih derecesinin 0'dan büyük belli bir değer almasını sağlamak adına (14) formülü yerine aşağıdaki gibi parametrik bir formül kullanılması daha makul olabilir:

$$
\mu^{H a t}\left(s_{b}, l, s_{a}\right)=\frac{1}{\left(1+\mu^{Y o g}\left(s_{b}, l, s_{a}\right)\right)^{w}}
$$

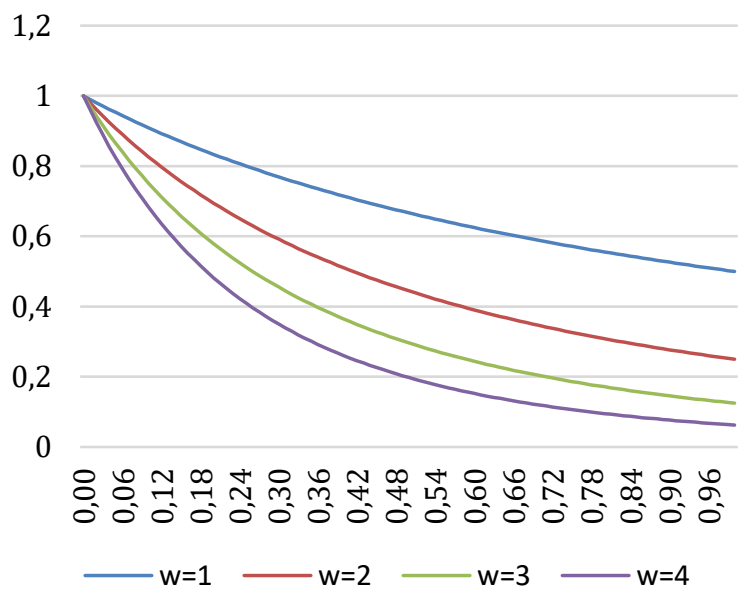

Şekil 2. Bulanık hat tercih derecesinin otobüs içi yoğunluk oranına bağlı parametrik şekilde belirlenmesi.

(15) formülündeki $w>1$ parametresine çeşitli değerler vermekle tam dolu otobüs için de bulanık hat tercih derecesinin 0'dan büyük bir değer olması garanti edilebilir (Şekil 2).

$s_{1}, s_{2} \in S$ her hangi iki durak olsun. $s_{1}$ durağına göre $s_{2}$ durağının bulanık komşuluk ilişkisi $\mu_{s_{1}}\left(s_{2}\right) \in[0,1]$ üyelik fonksiyonu aracılığıyla tanımlanabilir. Nasibov ve ark. [17] çalışmasında bu ilişkinin, duraklar arası mesafe, durak güvenlik derecesi, duraktan geçen hatların yoğunluğu gibi kriterler dikkate alınarak hesaplanması yöntemlerine değinilmiştir. Bazı durumlarda bu üyelik fonksiyonunun (16) formülünde belirtildiği gibi belli bir $\gamma$-seviye kümesine göre tanımlanmış kesin ilişki olan hali kullanılabilir: 


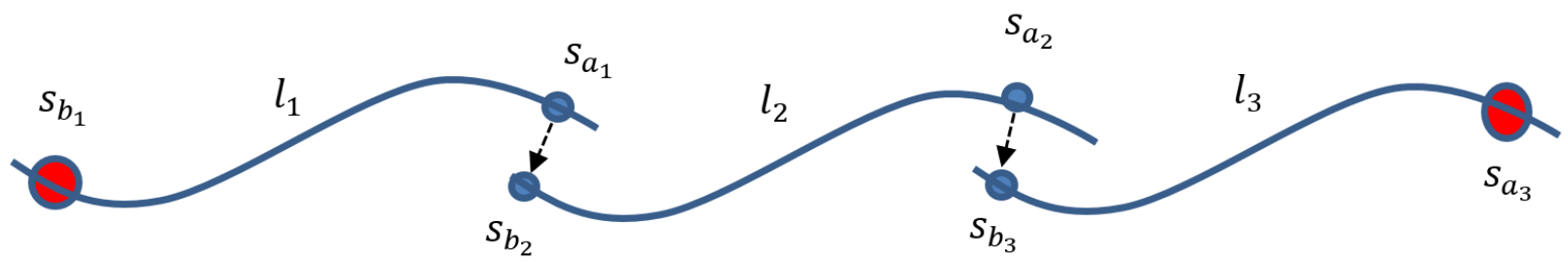

Şekil 3. İki transfer içeren olası bir güzergah örneği.

$$
\mu_{s_{1}}^{\gamma}\left(s_{2}\right)=\left\{\begin{array}{rr}
1, & \text { if } \mu_{s_{1}}\left(s_{2}\right) \geq \gamma \\
0, & \text { d.d. }
\end{array}\right.
$$

Belli bir yürüme mesafesi yarıçapında tüm durakların tercih dereceleri aynı kabul edildiği durumlarda duraklar arası (16) ilişkisi tercih edilmelidir.

Belli bir $s_{O}$ başlangıç duragından $s_{D}$ bitiş durağına giden $m$ sayıda olası bağlantı içeren olası bir güzergâhı aşağıdaki gibi işaret edilecektir:

$$
\begin{aligned}
\pi_{S_{O}, S_{D}}=< & \left(s_{b_{1}}, l_{1}, s_{a_{1}}\right),\left(s_{b_{2}}, l_{2}, s_{a_{2}}\right), \ldots \\
& \ldots,\left(s_{b_{m}}, l_{m}, s_{a_{m}}\right)>
\end{aligned}
$$

Açıktır ki, bu güzergahın tercih edilebilir olması için aşağıdaki koşulların sağlanması gerekecektir:

$$
\begin{gathered}
s_{b_{1}}=s_{O} ; \\
s_{a_{m}}=s_{D} ; \\
\mu^{\text {line }}\left(s_{b_{t}}, l_{t}, s_{a_{t}}\right)>0, t=1, \ldots, m, \\
\mu_{s_{a_{t-1}}\left(s_{b_{t}}\right)>0, t=2, \ldots, m .}
\end{gathered}
$$

Yukarıdaki (21) formülündeki $\mu_{s_{a_{t-1}}}\left(s_{b_{t}}\right), t=2, \ldots, m$, gösterimi, güzergahtaki $(t-1)$ numaralı olası bağlantının son durağı $s_{a_{t-1}}$ ile bir sonraki olası bağlantının ilk durağı olan $s_{b_{t}}$ aralarında yürüme mesafesinin olduğunu göstermektedir. (18) eşitliği, rotanın başlangıç durağının $s_{O}$ menşe durağına, benzer șekilde (19) eșitliği ise rotanın son durağının $s_{D}$ hedef durağına eşit olduğunu göstermektedir. Açıktır ki, $m$ sayıda olası bağlantıdan oluşan $\pi_{S_{O}, S_{D}}$ güzergâhındaki hat transfer sayısı $(m-1)$ 'e eșit olacaktır. Şekil 3'te, üç adet olası bağlantıdan oluşan bir olası güzergah örneği verilmiştir.

Yukarıdaki (17) formülüyle tanımladığımız olası güzergahın bulanık tercih derecesi, onu oluşturan olası bağlantıların tercih derecelerinin minimumu olarak (22) formülünde belirtilen şeklinde tanımlanabilir:

$$
\mu\left(\pi_{S_{O}, S_{D}}\right)=\left[\Lambda_{t=1}^{m} \mu^{H a t}\left(s_{b_{t}}, l_{t}, s_{a_{t}}\right)\right]
$$

\subsection{Optimal Güzergah Öneri Modeli ve Çözüm Algoritması}

En kısa mesafe, en az transfer sayısı, en kısa yürüme mesafesi gibi farklı kriterlerle optimal güzergah öneri modelleri çeşitli çalışmalarda ele alınmıştır [11-16]. Bu çalışmaların hepsinde durak yürüme mesafeleri ve hat bağlantıları sadece klasik $0 / 1$ mantığına dayanmaktadır. Güzergah için bulanık tercih derecesinin oluşturulması modeli ilk kes Nasibov ve ark. tarafından [17] çalışmasında önerilmiştir. Fakat [17] çalışmasında güzergahın bulanık tercih derecesi sadece transfer durakları arasındaki bulanık ilişki kullanılarak oluşturulmaktadır. Bu çalışmada ise önerilen (22) formülünde ise güzergah tercih derecesi, otobüs içi yoğunluğa dayalı olarak olușturulmaktadır. Bu bakımdan yolcuya önerilen güzergah sadece durak yakınlıklarını değil, yolculuk yapılacak otobüslerin iç doluluk oranlarını dikkate almaktadır. Özellikle günümüz pandemi sürecinde bu göstergenin çok önemli olduğu açıktır.

Güzergahın tercihinde önemli olan diğer bir gösterge de güzergahın uzunluğudur. Olası bir $\pi_{S_{O}, S_{D}}$ güzergâhında yolun toplam uzunluğu, geçtiği durakların toplam sayısı olarak aşağıdaki şekilde gösterilir:

$$
\left|\pi_{S_{0}, S_{D}}\right|=\sum_{t=1}^{m}\left|\left(s_{b_{t}}, l_{t}, s_{a_{t}}\right)\right|,
$$

Burada $\left|\left(s_{b_{t}}, l_{t}, s_{a_{t}}\right)\right|$ gösterimi, bir $l_{t}$ hatında $s_{b_{t}}$ biniş durağından $s_{a_{t}}$ iniş durağına kadar otobüsün geçtiği durakların sayısını gösteriyor. $\pi_{S_{O}, S_{D}}$ güzergahının toplam uzunluğu, güzergahın ana niteliği olarak ele alınabilir. Ayrıca, $(m-1)$ 'e eşit olan hatlar arası transfer sayısı güzergahın bir başka önemli özelliği olarak ele alınabilir.

Böylelikle, belirli $s_{O}$ durağından $s_{D}$ durağına giden optimal güzergahı bulmak amacıyla oluşturulan çok kriterli optimal güzergah öneri problemi aşağıdaki gibi tanımlanabilir:

$$
\begin{gathered}
\mu\left(\pi_{S_{O}, S_{D}}\right) \rightarrow \max \\
\left|\pi_{S_{X}, S_{Y}}\right|=\sum_{t=1}^{m}\left|\left(s_{b_{t}}, l_{t}, s_{a_{t}}\right)\right| \rightarrow \min \\
m \rightarrow \min
\end{gathered}
$$

s.t.:

$$
\begin{gathered}
s_{b_{1}}=s_{O} \\
s_{a_{m}}=s_{D} \\
L S\left(l_{t}, s_{b_{t}}\right) \geq 1, t=1, \ldots, m,
\end{gathered}
$$




$$
\begin{gathered}
L S\left(r_{t}, s_{a_{t}}\right)>L S\left(r_{t}, s_{b_{t}}\right), t=1, \ldots, m, \\
s_{b_{t}}, s_{a_{t}} \in S, t=1, \ldots, m, \\
l_{t} \in L, t=1, \ldots, m .
\end{gathered}
$$

Yukarıdaki (24) kriteri güzergahın olabildiğince yüksek tercih derecesinin olmasını, (25) kriteri, olası yollar arasından mümkün olduğunca en kısa güzergahın seçilmesini, (26) kriteri ise güzergah boyunca transfer sayısını en aza indirmeyi sağlayacaktır. Böylece, (24)-(26) amaç kriterleri ile tanımlanan problem, çok kriterli karar verme problemidir. Bu durumda problemin çözüm uzayı Pareto optimal çözümlerinden oluşacaktır. (24)-(32) probleminin karar değişkenleri (31) formülünde belirtilmiş duraklar ve (32) formülünde belirtilmiş hatlardır. Böylece problemin çözümü, her bir olası bağlantı için $S \times L \times S$ şeklinde kesikli kartezyen çarpım uzayında aranacaktır. Genel çözüm ise, güzergahtaki toplam $m$ olası bağlantı sayısı olmak üzere, $m \times S \times L \times S$ uzayında olacaktır.

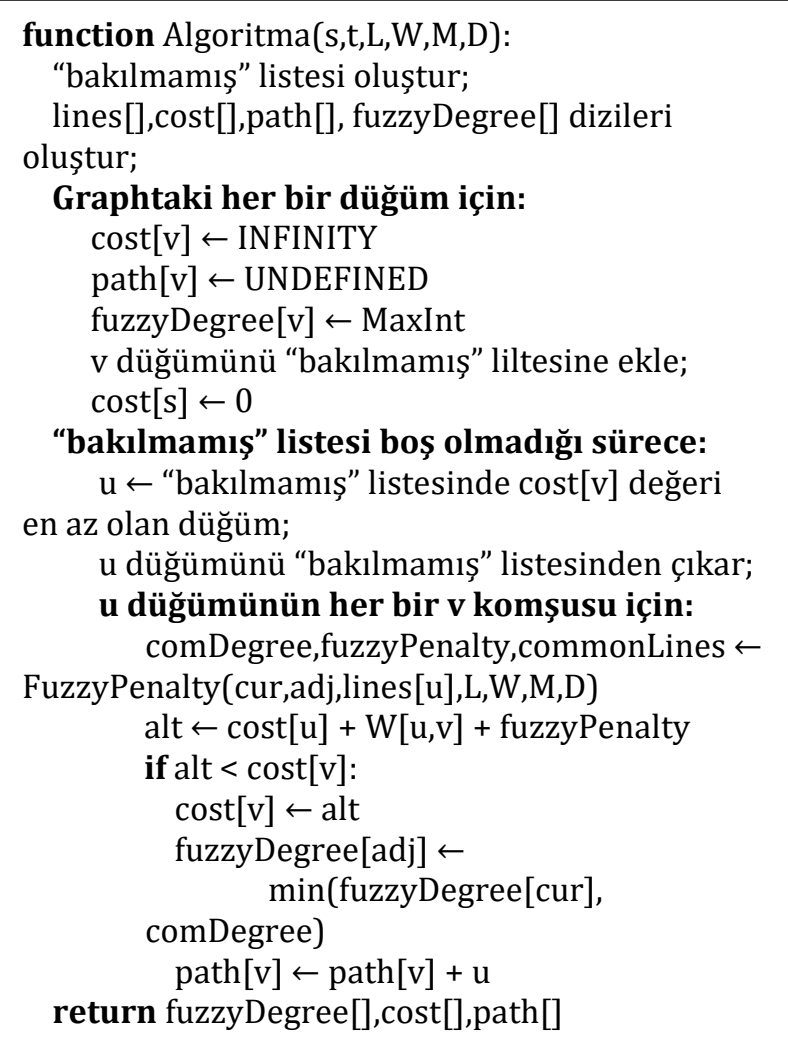

Şekil 4. Bulanık ceza fonksiyonu kullanan Dijkstra algoritmasının kabakodu.

Optimal güzergah öneri modeli olarak, en kısa yol ve en az transfer problemi [11-13] çalışmalarında ele alınmıştır. Problemin çözümü için Dijkstra benzeri algoritmalar önerilmiştir. Ayrıca, literatürde Dijkstra algoritmasına yönelik bazı bulanık yaklaşımlar da vardır. Kang [19] çalışmasında, graftaki kenarların uzunlukları bulanık aralıklar olarak kabul edilir ve bu probleme bir çözüm algoritması verilir. Deng ve ark.
[20] çalışmasında, dügümler arasındaki kenarların uzunlukları üçgen veya yamuk bulanık sayılar şeklinde ele alınmıștır. Söz konusu çalıșmada, bulanık sayıların dereceli ortalama entegre temsili kavramı, bulanık uzunluktaki kenarlarda toplama ve karşılaştırma işlemlerini gerçekleştirmek için kullanmıştır. Bu nedenle, Dijkstra algoritması, bulanık uzunluklu kenarlara sahip en kısa yolu bulacak şekilde genişletilmiștir. Fakat, [19] ve [20] çalışmalarından farklı olarak, bu çalışmada ek kriter olarak bulanık derecelendirme kriteri olan (24) kriteri eklenerek yeni bir bulanı optimizasyon problemi önerilmektedir. Önerilen bulanık çok kriterli modelin çözümü için, bulanık ceza fonksiyonu kullanan yeni bir bulanık Dijkstra benzeri algoritma kullanılmaktadır. Algoritmanın kabakodu Şekil 4'te verilmiştir. Algoritmada, bulanık ceza değerlerinin hesaplanması için çağrılan BulanıkCeza() fonksiyonunun kabakodu Şekil 5'de verilmiştir.

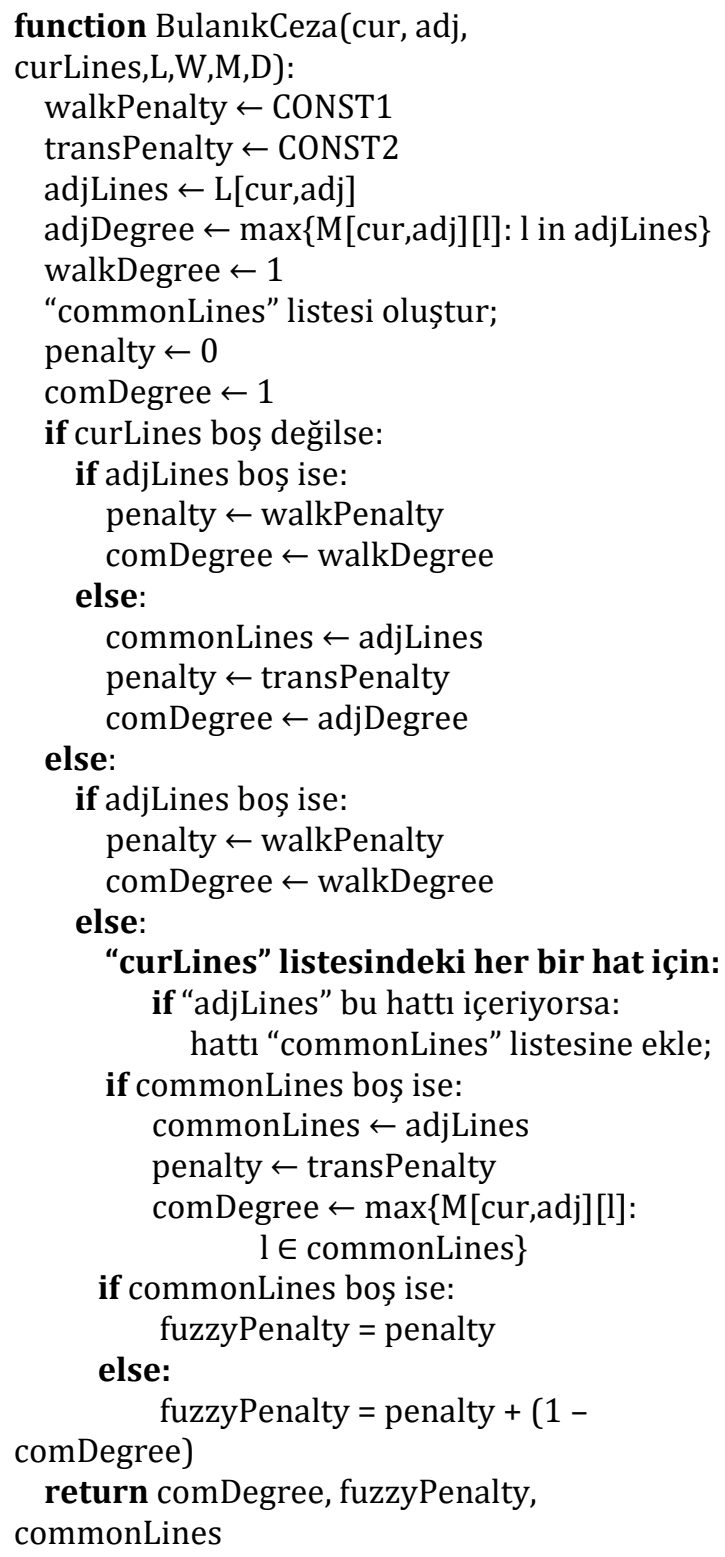

Şekil 5. BulanıkCeza() fonksiyonunun kabakodu. 


\section{Bulgular}

$\mathrm{Bu}$ çalışmada, İzmir şehir içi toplu taşıma ağının verileri kullanılarak hesaplama denemeleri yapılmıştır. İzmir'de toplu taşımadan sorumlu idare, İzmir BB ESHOT Genel Müdürlügüdür. ESHOT, İzmir şehir merkezine ve İzmir Büyükşehir Belediyesi sınırları içindeki çevre yaşam birimlerine hizmet vermektedir. İzmir toplu taşıma ağı, 6475 durağı ve 574 gidiş-dönüş hattı ile dünyadaki gelişmiş toplu taşıma ağına sahip şehirler arasında yer almaktadır. İzmir otobüs filosu 1396 otobüsle günde ortalama 13.884 sefer yapmaktadır [21]. İzmir'de otobüs, metro, tramvay ve feribot dahil olmak üzere çeşitli toplu taşıma ağları kullanılmaktadır. 1999 yılından beri, İzmir'de tüm toplu taşıma araçlarına biniş için akıllı kartlar kullanılmaktadır. Akıllı kartlarla günde yaklaşık 1,5 milyon işlem gerçekleştiriliyor. Akıllı kart verileri, kentsel toplu taşıma ağını analiz etmek ve optimum planlama için çok önemli bir veri kaynağıdır.

Gerçek biniş verileri dikkate alınarak otobüs içi yoğunluk oranlarını belirlemek için kullanılan yöntemler bölüm 2.1'de açılklanmıștı. Ancak, hesaplama deneylerinde önerilen modelin ve çözüm algoritmasının performansını değerlendirmek için otobüs içi yoğunluğa bağlı hat tercih dereceleri [0.5, 1.0] arasında üretilmiş rastgele gerçek sayılar olarak ele alınmıştır. Hesaplamalar i7, 2.5 GHz, 8GB RAM, 256 GB SSD özellikli dizüstü bilgisayarda Python 3 dilinde yazılmış uygulama ile yapılmıştır.

Önerilen bulanık modelin çözüm algoritmasıyla, İzmir toplu ulaşım ağından rasgele seçilen 100 çift durak arasında bulunan optimal rota sonuçları Tablo 1'de verilmiştir. Tablo 1 'de gösterilen yCeza ve trCeza değerleri, uygun olarak, duraklar arasında tekrar yürüme ve hat değiștirilmesinde kullanılan ceza değerleridir. Tablonun satırları, sırasıyla ceza fonksiyonu kullanan bulanık kritersiz model ve bulanık kriter kullanılan yeni modele karşsılık gelen satırlardır. Ayrıca, her model için farklı yCeza ve trCeza değerleri için üretilen yolların ortalama tercih dereceleri Şekil 6'da verilmiștir. Tablo 1 ve Şekil 6'dan görülebileceği gibi, aynı ceza değerleri kullanıldığı durumlarda, araçla gidilen ortalama mesafe ve ortalama hat transfer sayıları yaklaşık olarak aynı olmasına karşın, önerilen bulanık modelin çözümü olarak üretilen yolların ortalama tercih dereceleri daha yüksektir (tablodaki koyu değerler). Görüldüğü üzere, önerilen modelin çözümü olarak yaklaşık $\% 11,5$ daha yüksek tercih dereceli yollar üretilmiştir. Buna karşılık, bulanık modelin çözümü için ortalama $\% 2,2$ daha fazla bilgisayar zamanı harcanmıştır. Gerçek değeri 0,5 saniyenin altında olan bu zaman gecikmesi, modelin pratik kullanımını fazla etkilemeyeceği açıtır.

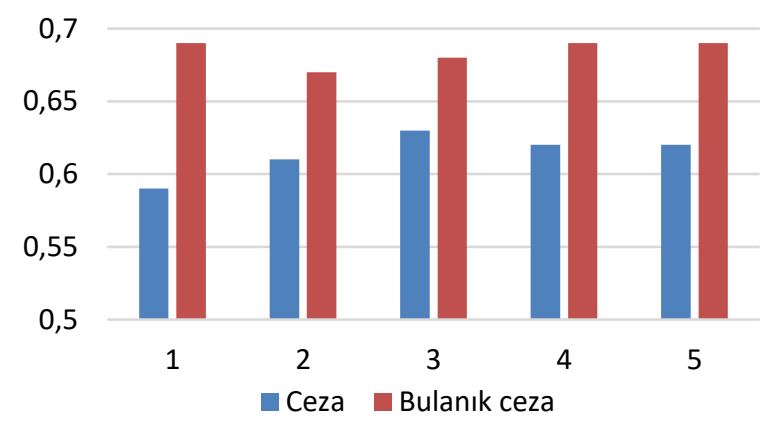

Şekil 6. Rotaların ortalama tercih dereceleri.

Tablo 1. Rastgele oluşturulmuş 100 başlangıç-hedef durak çifti için hesaplanan optimal rotaların ortalama göstergeleri.

\begin{tabular}{lcccc}
\hline \multicolumn{1}{c}{ Model } & $\begin{array}{c}\text { Araçla ortalama } \\
\text { mesafe (km) }\end{array}$ & $\begin{array}{c}\text { Ortalama } \\
\text { transfer sayısı }\end{array}$ & $\begin{array}{c}\text { Yolun ortalama } \\
\text { tercih derecesi }\end{array}$ & $\begin{array}{c}\text { Ortalama çalışma } \\
\text { süresi (saniye) }\end{array}$ \\
\hline $\begin{array}{l}\text { Ceza kullanımı } \\
\text { (wPenalty=1, } \\
\text { trPenalty=1) }\end{array}$ & 38,22 & 10,11 & 0,61 & 5,92 \\
\hline $\begin{array}{l}\text { Bulanı model } \\
\text { (wPenalty=1, } \\
\text { trPenalty=1) }\end{array}$ & 38,42 & 9,09 & $\mathbf{0 , 6 7}$ & 6,04 \\
\hline $\begin{array}{l}\text { Ceza kullanımı } \\
\text { (wPenalty=3, } \\
\text { trPenalty=3) }\end{array}$ & 38,33 & 6,35 & 0,63 & 5,72 \\
\hline $\begin{array}{l}\text { Bulanik model } \\
\text { (wPenalty=3, } \\
\text { trPenalty=3) }\end{array}$ & 38,15 & 6,35 & $\mathbf{0 , 6 8}$ & 6,07 \\
\hline $\begin{array}{l}\text { Ceza kullanımı } \\
\text { (wPenalty=5, } \\
\text { trPenalty=5) }\end{array}$ & 38,26 & 5,80 & 0,62 & 5,72 \\
\hline $\begin{array}{l}\text { Bulanik model } \\
\text { (wPenalty=5, } \\
\text { trPenalty=5) }\end{array}$ & 38,25 & 5,80 & $\mathbf{0 , 6 9}$ & 6,24 \\
\hline $\begin{array}{l}\text { Ceza kullanımı } \\
\text { (wPenalty=10, } \\
\text { trPenalty=10) }\end{array}$ & 38,76 & 5,27 & 0,62 & 5,80 \\
\hline $\begin{array}{l}\text { Bulanik model } \\
\text { (wPenalty=10, } \\
\text { trPenalty=10) }\end{array}$ & 38,77 & $\mathbf{0 , 6 9}$ & 6,13 \\
\hline
\end{tabular}




\section{Tartışma ve Sonuç}

Şehir içi toplu taşımacılığının yaygınlaştırılması gittikçe zorlaşan şehir içi trafik sorununa önemli derecede çözüm sağlayabilecek bir etkendir. Bunun için toplu taşıma araçlarının kullanımını kolaylaştıran uygulamaların olması önem kazanmaktadır. Bu çalışmada, bu alanda yapılacak uygulamalara destek olabilecek bir optimal güzergah öneri modeli ve çözüm algoritması önerildi. Önerilen modelde, olası optimal güzergâhın oluşturulmasında otobüs içi yoğunluğa dayanan bulanık tercih derecesi dikkate alınarak hat tercih kriteri geliştirildi. Özellikle bulaşıcı pandemi sürecinde otobüs içi yoğunluğun önem arz ettiği bir dönemde önerilen bu gibi yolculuk planlaması önemlidir. Oluşturulan modelde, klasik modellerin aksine, her güzergah kendi bulanık tercih derecesi eşliğinde kullanıcıya önerilmektedir. İzmir toplu taşıma ağı verilerine dayanan simülasyon denemelerinde, önerilen modelin ve çözüm algoritmasının, klasik yaklașımla kıyaslandığında daha yüksek tercih derecesi olan çözümler üretebildiği gösterildi.

Önceki bölümlerde de belirtildiği gibi, bu çalışmanın esas amacı toplu taşımada yolculuk için güzergah öneri problemine, otobüs içi bulanık yoğunluk derecesini de dikkate ala bilen bulanık bir bakış açısı getirerek, uygun matematik model ve çözüm algoritması oluşturmaktı. İlerde, şehir içi toplu taşıma kullanıcılarının çeşitli diğer bakış açılarını yansıtan bulanık en iyi güzergah modellerinin ve çözüm algoritmalarının oluşturulması yönünde çalışmaların yapılması düşünülmektedir.

\section{Etik Beyanı}

Bu çalışmada, "Yükseköğretim Kurumları Bilimsel Araştırma ve Yayın Etiği Yönergesi" kapsamında uyulması gerekli tüm kurallara uyulduğunu, bahsi geçen yönergenin "Bilimsel Araştırma ve Yayın Etiğine Aykırı Eylemler" başlı̆̆ı altında belirtilen eylemlerden hiçbirinin gerçekleștirilmediğini taahhüt ederiz.

\section{Kaynakça}

[1] Wilson, N.H., Zhao, J., Rahbee, A., The potential impact of automated data collection systems on urban public transportation planning. ss 75-99. Wilson, N.H., Nuzzolo. A., ed. 2009. Schedulebased modeling of transportation networks, Springer.

[2] Pelletier, M.P., Trepanier, M., Morency, C. 2011. Smart card data use in public transit: A literature review. Transportation Research Part C, 19, 557568.

[3] Bagchi, M., White, P.R. 2005. The potential of public transport smartcard data. Transport Policy, 12, 464-474.
[4] Morency, C., Trepanier, M., Agard, B. 2006. Analyzing the variability of transit users' behaviour with smart card data. Proceedings of the IEEE ITSC, Toronto, Ontario, Canada, 17-20 September, 44-49.

[5] Ceder, A. 2007. Public transit planning and operation: theory, modelling and practice. Oxford, Butterworth-Heinemann, 626s.

[6] Nasibov, E.N., Kuvvetli, U., Ozkilcik, M., Eliiyi, U. 2012. Origin-Destination Matrix Generation Using Smart Card Data: Case Study for Izmir. IV International Conference "Problems of Cybernetics and Informatics" (PCI'2012), Sep 1214, Baku, Azerbaijan, v.1, 188-191.

[7] Munizaga, M.A., Palma, C. 2012. Estimation of a disaggregate multimodal public transport origindestination matrix from passive smartcard data from Santiago, Chile. Transportation Research Part C, 24, 9-18.

[8] Barry, J., Newhouser, R., Rahbee, A., Sayeda, S. 2002. Origin and destination estimation in New York City with automated fare system data. Transportation Research Record, 1817, 183-187.

[9] Trepanier, M., Tranchant, N., Chapleau, R. 2007. Individual trip destination estimation in a transit smart card automated fare collection system. Journal of Intelligent Transportation Systems, 11(1), 1-14.

[10] Diker, A. 2015. Usage of fuzzy logic based data mining methods in analysis of public transportation data. Dokuz Eylul University, The Graduate School of Natural and Applied Sciences, Ph.D. Thesis, 29s.

[11] Bozyigit, A., Nasiboglu, E., Utku, S. 2018. Public Transport Route Recommender Regarding Multiple Factors. 3rd International Conference on Computer Science and Engineering (UBMK18), Sarajevo, 20-23 September, 12-16.

[12] Bozyigit, A., Alankus, G., Nasibov, E. 2018. A Public Transport Route Recommender Minimizing the Number of Transfers. Sigma J Eng \& Nat Sci, 9(4), 437-446.

[13] Bozyiğit, A., Alankuș, G., Nasiboğlu, E. 2017. Public transport route planning: Modified dijkstra's algorithm. International Conference on Computer Science and Engineering (UBMK-17), 5-8 Octrober, Antalya, 502-505.

[14] Wang, H., Hu, M., Xiao, W. 2010. A new public transportation data model and shortest-path algorithms. 2nd International Asia Conference on Informatics in Control Automation and Robotics (CAR 2010), 6-7 March, Wuhan, China, v. 1, 456459.

[15] Pun-Cheng, L. S. C., Chan, A. W. F. 2016. Optimal route computation for circular public transport 
routes with differential fare structure. Travel Behaviour and Society, 3, 71-77.

[16] Huang, Z., Li, J., Liu, X. 2009. Information Needs of Urban Transit Travelers-The Case of Wuhan China. ICCTP 2009: Critical Issues in Transportation Systems Planning Development and Management, 5-9 August, Harbin, China, 1-7.

[17] Nasibov, E., Diker, A., Nasibov, E. 2016. A multi criteria route planning model based on fuzzy preference degrees of stops. Applied Soft Computing, 49, 13-26.

[18] Currie, G., Delbosc, A. 2011. Exploring the trip chaining behaviour of public transport users in Melbourne. Transport Policy, 18(1), 204-210.
[19] Deng, Y., Chen, Y., Zhang, Y., Mahadevan, S. 2012. Fuzzy Dijkstra algorithm for shortest path problem under uncertain environment. Applied Soft Computing, 12, 1231-1237.

[20] Kang, J.G. 2013. The Minmax Regret Shortest Path Problem with Interval Arc Lengths. International Journal of Control and Automation, 6(5), 171180.

[21] ESHOT resmi web sayfası 2020. https://www.eshot.gov.tr/ (Erişim tarihi: 16.11.2020). 